\title{
O Que Nos Ensina o Coronavírus? ${ }^{1}$
}

\author{
Luigi Ferrajoli \\ Professor da Università degli Studi Roma Tre (Itália). luigi.ferrajoli@uniroma3.it
}

1. A pandemia do coronavírus está mudando e vai mudar ainda mais a vida de todos. Isso nos obriga a repensar a política e a economia e a refletir sobre o nosso presente, o nosso passado e o nosso futuro.

Em primeiro lugar é necessário falar sobre o nosso presente, e, portanto, sobre a resposta institucional - as limitações das nossas liberdades - que foi dada pelo nosso governo. Trata-se de uma resposta absolutamente necessária. Felizmente, na Itália, a nossa Constituição não prevê o estado de emergência, que está positivado em muitos outros sistemas jurídicos, como o francês, em que foi declarado em 24 de março de 2020, e o espanhol, no qual foi declarado em 14 de março de 2020. Isso é uma sorte. Estas instituições, como a experiência nos ensina, são extremamente perigosas em razão do caráter genérico dos seus pressupostos, que deixam em aberto espaços indefinidos para a arbitrariedade. Por exemplo, o artigo 16 da Constituição Francesa de 1958, que prevê o Estado de Urgência, o qual permite "medidas necessárias" não especificadas pelas "circunstâncias"; e o artigo 116 da Constituição espanhola de 1978, que prevê três estados de emergência - o estado de alarme, o estado de exceção e o estado de sítio (ou estado de cerco) -, que consistem, como diz a Lei Orgânica no 4/81, nas não menos indefinidas "medidas estritamente indispensáveis" para fazer frente a "circunstâncias extraordinárias" das mais diversas naturezas. Na Hungria, Orban concedeu a si próprio "plenos poderes" sem limites de tempo.

A nossa Constituição, porém, não permite exceções à democracia, mas, no entanto, igualmente permitiu, como evidência da não necessidade desses estados símiles de exceção, estabelecer medidas para travar o contágio, legitimadas unicamente para impor limites à liberdade de circulação, à liberdade de reunião e à liberdade pessoal. De fato, o artigo 16 prevê que a liberdade de circulação pode ser restringida por lei "por razões de saúde ou segurança"; o artigo 18 prevê que o exercício da liberdade de reunião pode ser proibido pelas "autoridades" "por razões comprovadas de segurança e proteção pública"; o artigo 32 prevê a eventual restrição da liberdade pessoal, como é a quarentena das pessoas infectadas, por meio da submissão a "tratamentos sanitários" obrigatórios "no interesse da comunidade". Por conseguinte, não se trata de limitações em branco, como a suspensão de direitos e do funcionamento normal dos órgãos constitucionais possibilitados por estados genéricos de sítio ou de exceção. Trata-se unicamente das limitações dessas três liberdades, exigidas pela garantia do direito à vida: um valor, a vida, cuja proteção representa a razão de ser de toda a lei e de toda a estrutura institucional.

Isso tudo, porém, não impede que para se limitar tais liberdades constitucionais dever-se-ia adotar sempre a forma de decreto-lei, e não a forma dos Decretos do Presidente do Conselho de Ministros (DPCMs), que contêm "disposições de aplicação" dos cinco decretos-lei produzidos pelo governo. Ao contrário destes DPCMs, na realidade o decreto-lei é um ato de ordem legislativa, sujeito ao controle do Parlamento e à apreciação sumária da constitucionalidade, no momento da sua emissão, pelo presidente

Tradução do italiano pelo professor doutor Doglas Cesar Lucas. PPGD da Unijuí. doglasl@unijui.edu.br 
da República. O Parlamento, por outro lado, permanece substancialmente alheio à discussão e à formulação destas regras, e somente será informado de 15 em 15 dias sobre as medidas adotadas, e isso é muito pouco.

Naturalmente, para se apoiar as restrições à livre-circulação, que são igualmente limitações da livre-circulação do vírus, não bastam apenas regras e sanções. É absolutamente necessário que todos compartilhem e tenham a consciência da necessidade de proteger a sua saúde e a sua vida e a dos outros. Devemos reconhecer que se operou um compartilhamento do problema e que a população cumpriu, em grande parte, as medidas estabelecidas. Acima de tudo, devemos manifestar a nossa admiração e gratidão ao trabalho dos médicos e enfermeiros que põem a sua vida em perigo. Em suma, a Itália está dando uma prova extraordinária de maturidade e de responsabilidade cívica: no espírito de sacrifício daqueles que têm de entrar em contato com os doentes, e na disciplina e sentido de responsabilidade com que as medidas destinadas a evitar o contágio são respeitadas pela grande maioria das pessoas.

Não se trata de medidas de menor importância, e, embora estas medidas sejam estabelecidas por normas gerais e abstratas, aumentam e dramatizam as desigualdades: entre os que podem ficar em casa e os que são obrigados a ir trabalhar, entre os que têm casa e os que não têm, entre os que têm grandes casas com jardins ou terraços e os que são obrigados a viver num quarto, entre os que estão sós e entre os pobres e os que vivem com as suas famílias. Pensemos, porém, sobretudo, nas prisões superlotadas; nos campos de ciganos; nas situações dramáticas dos sem-abrigo; nas massas de migrantes acampadas nas fronteiras da fortaleza Europa, ou, ainda, confinados em campos líbios, ou acampados em Lesbos ou em campos italianos; nos imigrantes ilegalizados e atirados para a rua pelo primeiro Decreto Salvini, que aboliu a autorização de residência por razões humanitárias. Pensemos, também, nos palestinos, presos naquela prisão ao ar livre que é a Faixa de Gaza e nos milhões de pessoas que, em todas as metrópoles - na América Latina, na África, na Índia -, vivem amontoadas em favelas pobres. Um surto de contágio entre estas pessoas desesperadas provocaria massacres dos quais, provavelmente, nem sequer teríamos conhecimento.

2. Ainda mais amarga é a reflexão, estimulada pelo vírus, sobre o nosso passado. Esta tragédia veio revelar a miopia das políticas governamentais, que, nos últimos dez anos, com o objetivo de reduzir os impostos, diminuíram as despesas de saúde pública na Itália, aboliram 70.000 leitos hospitalares, fecharam 359 hospitais ou enfermarias hospitalares e reduziram o número de pessoal de saúde, não substituindo milhares de médicos e enfermeiros aposentados. É evidente, nestas políticas irresponsáveis, um acordo substancial entre populistas e liberalistas, igualmente desinteressados na garantia do direito à saúde: primeiro, porque esta garantia nunca interessou, no futuro imediato, à grande maioria dos eleitores, mas apenas aos doentes, na sua maioria idosos; segundo, por seu desinteresse pela saúde pública e a sua preferência pelo sistema privado de saúde.

De repente a epidemia do coronavírus, com a sua carga diária de mortos e infectados, colocou os cuidados de saúde no centro das preocupações de todos. Ao potencialmente infectar, indistintamente, todas as pessoas, afastou a economia da sua centralidade passada; expôs o valor inestimável da saúde pública e o seu caráter universalista e gratuito; tem instado e promovido a multiplicação das unidades de cuidados intensivos e a produção de equipamento de cuidados de saúde adequado; e, finalmente, mostrou a irracionalidade - e, na 


\section{Humanos}

Democracia

minha opinião, a inconstitucionalidade - da existência, na Itália, de 20 sistemas de saúde diferentes, tantos quantos são as regiões existentes, em contradição com a igualdade dos direitos fundamentais em que se baseiam a solidariedade e a unidade nacional.

Não só isso. O coronavírus apanhou todos os governos, incluindo o nosso, despreparados, revelando, especialmente com as respostas iniciais inadequadas, a sua irresponsável imprevidência. Embora o perigo de uma pandemia tenha sido previsto já em setembro de 2019 por um relatório do Banco Mundial, nada foi feito para enfrentá-lo. Quando se trata de guerra, são realizados exercícios militares em todos os países, constroem-se bunkers, realizam-se simulações de ataques e se aplicam técnicas de defesa. Contra o perigo anunciado de uma pandemia, porém, não se fez absolutamente nada. O paradoxo foi alcançado com o equipamento médico. Nas previsões de guerra, as armas, os tanques e os mísseis nucleares estão a acumular-se e a tornar-se cada vez mais mortais. O coronavírus, por outro lado, fez-nos descobrir a incrível falta de leitos hospitalares, unidades de cuidados intensivos, respiradores, materiais de higiene e máscaras. Revelou a absurda escassez de médicos e enfermeiros e a ausência total de uma organização de cuidados domiciliares. Em suma, apercebemo-nos de que nos faltavam as medidas mais básicas para lidar com o contágio.

Naturalmente, esta imprevidência está revelando-se da forma mais dramática em alguns países, como nos Estados Unidos, que carecem de saúde pública. Nestes países, aqueles que não possuem um seguro adequado não poderão receber tratamento. Dezenas de miIhões de pessoas pobres serão abandonadas à própria sorte. Este despreparo e imprevidência são, em grande medida, inevitáveis nos países pobres. São, porém, apenas o sinal de uma loucura incrível quando dizem respeito às grandes potências, poderosas em termos de armas e finanças, mas muito fracas quanto à defesa da vida e da saúde. Nos Estados Unidos, Trump cancelou a modesta reforma no sistema de saúde proposto por Obama, deixando milhões de pessoas pobres sem possibilidade de tratamento. A maior potência do mundo continua a produzir armas nucleares, mas encontra-se desprovida de respiradores e de testes para a Covid-19, sendo responsável por dezenas, ou talvez, centenas de milhares de mortes.

3. Por último, uma reflexão sobre o nosso futuro: sobre o futuro do nosso país, da Europa, do mundo. Esta epidemia demonstrou o enorme valor da nossa saúde pública, gratuita e acessível a todos, nos termos do direito universal à saúde previsto no artigo 32 da nossa Constituição. Demonstrou, a par da miopia das políticas do passado, a necessidade de se reforçar o nosso sistema de saúde, aumentando o número de hospitais, camas, unidades de terapia intensiva, médicos e enfermeiros e o equipamento necessário, desde testes para verificação do vírus a respiradores e máscaras. Finalmente, demonstrou a superioridade das organizações políticas, que têm um sistema de saúde público, sobre aqueles em que a saúde e a vida são confiadas aos seguros e aos cuidados dos planos de saúde privados. Não podemos sequer imaginar o que poderá acontecer nos Estados Unidos, onde apenas um teste para Covid-19 custa alguns milhares de dólares, ou em muitos países da América Latina, para não falar da África e de grande parte da Ásia.

Há, ainda, um conjunto de outros ensinamentos que provém da natureza global desta epidemia e que já se difundiu por todo o mundo: a necessidade de combatê-la com medidas eficazes e, sobretudo, homogêneas. Basta que alguns países tomem medidas inadequadas para ressurgir, com os deslocamentos humanos e os perigos de contágio em todos os outros 
países. Por isso, repito, a necessidade de se adotar medidas uniformes em todo o território nacional, confiadas, portanto, ao Estado central e não às Regiões. Daí, sobretudo, a necessidade de uma resposta, pelo menos, em âmbito europeu e, no futuro, na esfera mundial. Em vez disso, a União Europeia está perdendo uma oportunidade valiosa para demonstrar a sua unidade e a sua razão de ser. Até agora, os seus 27 países membros têm avançado de modo disperso, adotando cada um estratégias distintas em momentos diferentes e quase sempre tardiamente: desde as medidas mais rigorosas da Itália e da Espanha até as medidas mais brandas da França e da Alemanha. Uma gestão comum da epidemia, no entanto, seria até mesmo imposta pelos Tratados. $\mathrm{O}$ artigo 168 do Tratado sobre o Funcionamento da União, dedicado à saúde pública, após ter declarado que "a União assegura um elevado nível de proteção da saúde humana", estabelece que "os Estados-Membros coordenam entre si, em articulação com a Comissão, as suas respectivas políticas", e que "o Parlamento Europeu e o Conselho podem igualmente adotar medidas de proteção da saúde humana, especialmente para combater os grandes flagelos que se propagam além-fronteiras". Ademais, o artigo 222, intitulado "cláusulas de solidariedade", institui que "a União e os Estados-membros atuarão conjuntamente num espírito de solidariedade caso um Estado-membro seja vítima de uma calamidade natural". O que aconteceu, contudo, é que a União Europeia - cuja Comissão tem entre os seus membros um comissário para a Saúde, outro comissário para a Coesão e, até mesmo, um comissário para a Gestão de Crises - renunciou à possibilidade de ter em suas mãos a gestão da epidemia e definir diretivas sanitárias uniformes para todos os seus Estados membros. Se a esta abdicação do seu papel acrescentarmos o doloroso conflito entre soberanistas do Norte e soberanistas do Sul a propósito da emissão de eurobonds, cujo valor como sinal de solidariedade é muito mais político do que econômico, é evidente o risco de suicídio da União, pois revela ser capaz de impor aos Estados membros apenas sacrifícios em benefício de orçamentos equilibrados, e não, também, medidas sanitárias em benefício da vida dos seus cidadãos.

Não só isso. O caráter planetário desta epidemia oferece uma confirmação dramática da necessidade e da urgência de uma resposta global a símiles emergências que somente podem advir da criação de uma esfera pública supraestatal: precisamente do desenvolvimento de um constitucionalismo planetário, tal como proposto e promovido pela escola "Costituente Terra", que inauguramos em Roma no dia 21 de fevereiro passado (2020). Essa emergência tem, de fato, um caráter específico em relação a todas as outras, incluindo as ecológicas e as nucleares. Em razão do seu terrível número diário de mortes em todo o mundo, essa torna ainda muito mais visível e intolerável, do que qualquer outra emergência, a falta de instituições de garantias globais adequadas, que deveriam ter sido introduzidas para instituir as muitas cartas internacionais dos direitos humanos. Mais do que qualquer outra catástrofe, essa torna-se, portanto, a mais urgente e, ao mesmo tempo, mais universalmente compartilhada a necessidade de colmatar esta lacuna.

Pode, portanto, haver um despertar da razão. Já existe uma Organização Mundial de Saúde, mas essa não dispõe nem mesmo dos meios e dos aparelhos necessários para levar medicamentos que salvam vidas aos países pobres do mundo - originalmente pouco mais de 200, hoje 460 -, e há 40 anos ela mesma estabeleceu que estes deveriam ser universalmente acessíveis a todos, cuja falta causa 8 milhões de mortes por ano. Atualmente, a epidemia glo- 
bal afeta a todos, sem distinções entre ricos e pobres. Isto poderia, portanto, constituir uma oportunidade para fazer da OMS uma verdadeira instituição de garantia global, dotada dos poderes e meios necessários para enfrentar as crises com medidas racionais e adequadas, não condicionadas por interesses políticos ou econômicos contingentes, mas destinadas unicamente a garantir a vida de todos os seres humanos.

Em suma, é possível que a pandemia do coronavírus, afetando todo o gênero humano, sem distinção de nacionalidade e riqueza, gere a consciência da nossa fragilidade comum, da nossa interdependência e do nosso destino comum. É, com efeito, desejável que, para além do fragmento de um constitucionalismo planetário em termos da saúde, valha a pena sensibilizar para o fato de estarmos todos expostos, embora não imediata ou diretamente, a outras catástrofes graves - ambientais, nucleares, humanitárias -, cuja prevenção requer outras instituições de garantia global; por exemplo, a criação de uma propriedade estatal planetária para proteger bens comuns, como a água, o ar e as grandes geleiras e florestas; a proibição de armas nucleares e convencionais, cuja disseminação é responsável por centenas de milhares de assassinatos todos os anos; o monopólio da força militar pela ONU; e um sistema fiscal global capaz de financiar os direitos sociais à saúde, à educação e à alimentação básica, embora já proclamado em muitas cartas internacionais.

Parecem hipóteses utópicas. Em vez disso, são as únicas respostas racionais e realistas para os grandes desafios de que depende o futuro da humanidade. Esta epidemia colocou na ordem do dia a necessidade de um constitucionalismo global e de uma esfera pública planetária no interesse de todos. Todos os pré-requisitos para este salto civilizacional existem. De fato, nas últimas semanas desenvolveu-se um extraordinário e inesperado sentimento de solidariedade entre as pessoas e entre os povos, que se manifestou nos diferentes tipos de ajuda e na vinda de médicos da China, de Cuba, da Polônia e mesmo da Albânia para a Itália. Pela primeira vez na história, a tragédia, que nos une a todos, talvez esteja a gerar a percepção de um interesse público da humanidade muito mais geral do que todos os interesses nacionais e partidários: o interesse na sobrevivência da raça humana, como único povo, unido pelos mesmos direitos e pelos perigos comuns de catástrofes globais. 